\title{
Validation of active forest fires detected by MSG-SEVIRI by means of MODIS hot spots and AWiFS images
}

\author{
A. CALLE†, F. GONZÁLEZ-ALONSO and S. MERINO DE MIGUEL \\ Remote Sensing Laboratory, University of Valladolid, Dp. Applied Physics, Faculty of \\ Sciences, 47071-Valladolid, Spain \\ Remote Sensing Laboratory, INIA, Ministry of Education and Science, Crta. ha \\ Coruña, km. 7.5, 28040 Madrid, Spain \\ EUIT Forestal, Universidad Politécnica de Madrid, Avda. de Ramiro de Maeztu s/n, \\ 28040 Madrid, Spain
}

\begin{abstract}
The detection of forest fires and the determination of their parameters have been usually carried out by polar-orbit sensors: AVHRR, (A)ATSR, BIRD, and MODIS mainly. However, their time resolution prevents them from operating in real time. In contrast, the new geostationary sensors have very appropriate capacities for the observation of the Earth and monitoring of forest fires, as is being proved. GOES, MSG, and MTSAT are already operative, and they have led the international community to think that the global observation network in real time may become a reality. The implementation of this network is the aim of the Global Observations of Forest Cover and Land Cover Dynamics (GOFC/ GOLD) FIRE Mapping and Monitoring programme, focused internationally on taking decisions concerning the research of the Global Change. In this Letter, the operation in real time by the MSG-SEVIRI sensor over the Iberian Peninsula is studied. On the other hand, the reliability of validation results by means of polar sensors, with a finer spatial resolution, is difficult to analyse due to errors caused by confused location of fires. This Letter shows that fires detected by means of MSG-SEVIRI can be an useful option in order to estimate burnt areas at global scale, considering a spatial resolution of $40 \mathrm{~km}$.
\end{abstract}

\section{Introduction}

Forest fires play an important role in global climate change, being responsible for a significant amount of greenhouse gas emissions to the atmosphere (Crutzen et al. 1979). The information provided by the polar satellites has been of great help in the establishment of global observation systems and in the generation of fire-occurrence maps. In spite of the fact that detection results produced by polar-orbit sensors are not valid for providing early alarms, fire products created by these sensors have been identified by IGBP as a key input for the Global Change Analysis (Malingreau 1990).

The detection of high-temperature events (HTE) through geostationary satellites has been taken into account with the different perspective adopted for these platforms. The improvements introduced in the sensors have allowed geostationary satellites to be used beyond their meteorological operational uses, adapting them to Earth observation. This has been in response to the necessity of having a series of stable observations of fire activity for the analysis of the Global Change, changes in land use, and the monitoring risks (Justice and Korontzi 2001). In this sense, the 
Geostationary Operational Environmental Satellite (GOES) has been the worldwide reference for monitoring fires through geostationary platforms. Since 2000, the Geostationary Wildfire Automated Biomass Burning Algorithm (http://cimss.ssec. wisc.edu/goes/burn/wfabba.html) has been generating products for the Western Hemisphere in real time with a resolution of $30 \mathrm{~min}$ (Prins and Menzel 1992, 1994). This detection system has been operational within the NOAA NESDIS programme since 2002. The results provided by the GOES programme have been the starting point of a global geostationary system for fire monitoring initially integrated by four geostationary satellites that were already operational: the two USA GOES platforms, the European Meteosat Second Generation (MSG), and the Japanese Multifunctional Transport Satellite (MTSAT).

It is thought, in the international community among users, that the global realtime observation network, by means of GOES, MSG, and MTSAT satellites, might become a reality. The implementation of this network is the aim of the Global Observations of Forest Cover and Land Cover Dynamics (GOFC/GOLD) FIRE Mapping and Monitoring programme, internationally focused on taking decisions concerning the research of the Global Change. The GOFC/GOLD FIRE programme and the Committee on Earth Observation Satellites (CEOS) Land Product Validation held a workshop dedicated to the applications of geostationary satellites for monitoring forest fires. The workshop (the most relevant conclusions of which appear in Prins et al. 2004) was hosted by the European Organization for the Exploitation of Meteorological Satellites (EUMETSAT). Prins et al. (2001) also reveal the global vision of a future network of geostationary sensors dedicated to fire observations.

The European MSG-1 satellite, also called Meteosat-8, is the first of the second generation of geostationary satellites operated by EUMETSAT. The spin-stabilized MSG-1 satellite was put into orbit in August 2002. Its main sensor, and the most important one for the purpose of this work, is the Spinning Enhanced Visible and Infrared Imager (SEVIRI), with 11 spectral bands at $4.8 \mathrm{~km}$ of spatial resolution, with a sampling step of $3 \mathrm{~km}$, and one visible broadband (HRV) with a $1-\mathrm{km}$ sampling step in the nadir point. The scan of the full disk is completed every $15 \mathrm{~min}$. SEVIRI has three solar bands (centred at $0.75,0.63$, and $0.81 \mu \mathrm{m}$ ), one short-wave infrared $(1.6 \mu \mathrm{m})$, and eight infrared bands $(3.9,6.2,7.3,8.7,9.7,10.8,12.0$, and 13.4 $\mu \mathrm{m})$, all at 10-bit spectral resolution. The most important band is the $3.9-\mu \mathrm{m}$ band, with a saturation level of $335 \mathrm{~K}$. The improvements introduced in the new Meteosat satellites significantly expand their capabilities for the Earth observation (Schmetz et al. 2002). Concerning fire detection and retrieval of biomass combustion rates by means of SEVIRI, Roberts et al. (2005) and Wooster et al. (2005) show an application to southern Africa.

The capacity of the SEVIRI sensor for monitoring forest fires in near real time in the Mediterranean latitudes is the objective of several projects founded by ESA, as NOD (Near-Operational Demonstration of the Use of Satellite Systems for Fire Risk Management). Results from this project are shown by Calle et al. (2006). The objective of the work presented herein is to validate the results of SEVIRI hot-spot detection and to determine the appropriate spatial scale of validation related to climate-change studies.

\section{Region and imagery of study}

This study was carried out in Galicia (Spain). This region is situated north-west of the Iberian Peninsula, just to the north of Portugal, and it is the most humid part of 
Spain. The study area is as large as 2968165 ha. The forest area is mostly covered by conifers and eucalyptuses, and wildfires are usually small but frequent. During August 2006, almost 95000 ha were burnt over 8 days, leading to significant economic losses and major societal problems. Figure 1 shows a geographic detail of the Galicia region in Spain and the locations of the fires that occurred there.

The remotely sensed resources used consisted of data from three different sensors: MSG-SEVIRI, Terra\&Aqua-MODIS, and Resourcesat-1-AWiFS. The MSGSEVIRI sensor provided hot-spot detection data, according to the methodology explained in the next section. Images from the period 1 to 20 August 2006 were considered in order to span the period of main fire activity, which was concentrated between 4 and 13 August. During the mentioned period, all available day-and-night images were processed in real time, resulting in 1920 scenes. SEVIRI images were provided by the Remote Sensing Laboratory of University of Valladolid a receiving station is running in real time.

In order to validate SEVIRI fire detection results, two other sources of information have been used: (i) hot spots from Terra\&Aqua-MODIS belonging to the period 1 to 20 August 2006, generated by the MODIS LP DAAC (Thermal Anomalies - MOD14/MYD14) and, (ii) a burnt area map performed using a Resourcesat-1-AWiFS image dated on the $21^{\text {th }}$ of August 2006. The latter was produced at $60 \mathrm{~m}$ spatial resolution, so it must be taken into account that it could include a lot of very small fires (González-Alonso et al. 2007).

\section{Methodology}

Applied methodology of fire detection using MSG-SEVIRI data was proposed by Calle et al. (2006) where consecutive scenes of channel $3.9 \mu \mathrm{m}$ were used in order to detect small thermal anomalies due to the starting of fire, and a potential minimum size of fire is estimated for different geographical latitudes. The methodology

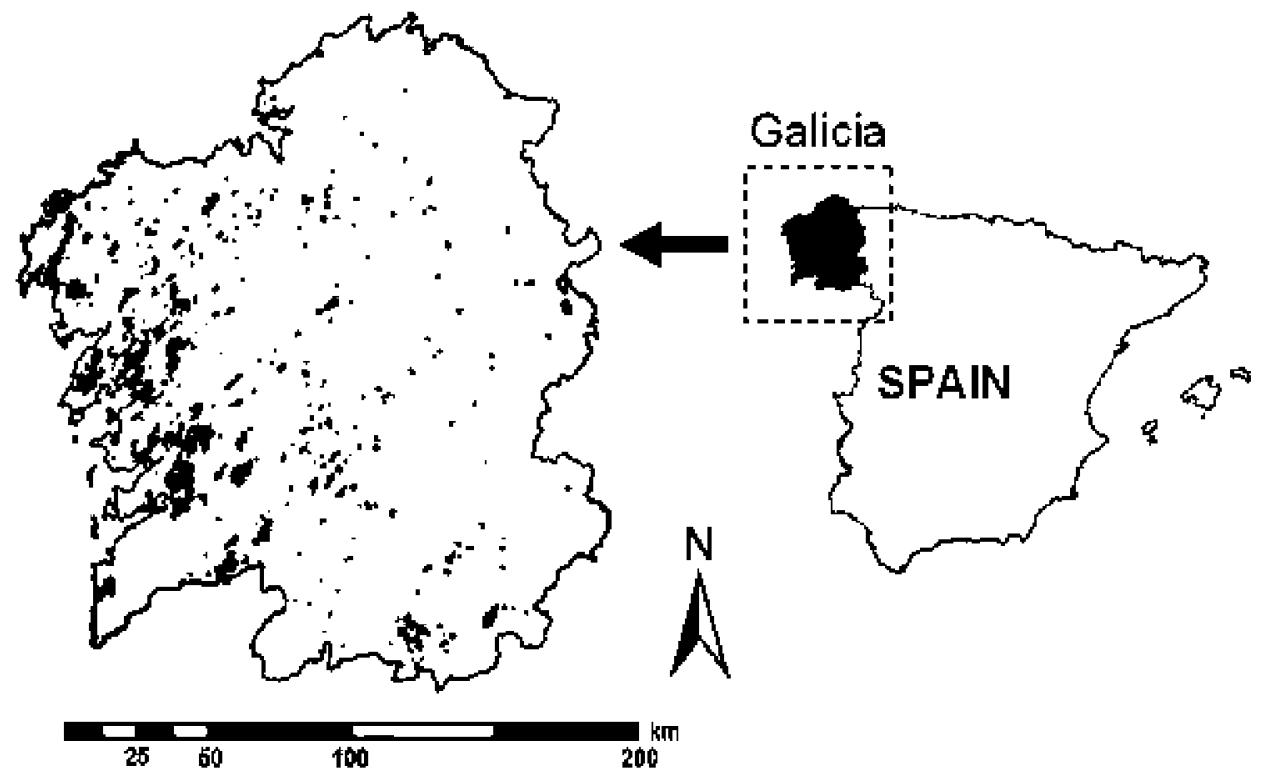

Figure 1. Geographic detail of Galicia and locations of forest fires (burnt areas from the AWiFS sensor), analysed in the validation process. 
proposed to detect fire outbreak is not longer valid as the fire keeps developing since the temperature differences between consecutive scenes undergo strong variations. More over, the frequent appearance of saturated pixels causes sharp changes that cannot be analysed. Once a fire starts, a simple method based on spatial contextual analysis is applied in order to support fire detection during the period in which fire is still active.

Detection methods using other sensors are sometimes based on physical models. However, statistical models have shown more accurate results and are easier to apply. Contextual models have been operating on AVHRR and MODIS for a long time (Kaufman and Justice 1998, Li et al. 1999, Giglio et al. 2003, Ichoku et al. 2003). A contextual analysis, through a spatial matrix of $N \times N$ pixels, is carried out on detected fires to verify permanency, thus establishing the required statistical parameters: average and standard deviation. According to previous results, obtained from the analysis of a database of fires validated by MODIS, the best window size is $N=9$. The detection test ultimately involves designating as 'affected' any pixel fulfilling the following inequalities:

$$
\begin{aligned}
& T_{3.9}>\mu_{3.9}+f \sigma_{3.9} \\
& T_{3.9}-T_{10.8}>\mu_{3.9-10.8}+f \sigma_{3.9-10.8},
\end{aligned}
$$

where $\mu_{3.9}$ and $\sigma_{3.9}$ are the average and the standard deviation values in the $3.9 \mu \mathrm{m}$ channel, and $\mu_{3.9-10.8}$ and $\sigma_{3.9-10.8}$ are the average and the standard deviation values in the difference of 3.9-10.8 $\mu \mathrm{m}$ channels, respectively. Although the contextual algorithm has been widely used for other sensors, values have not yet been established for the size of the matrix applicable to SEVIRI $(9 \times 9$ in this case) and the statistical factor $f$. A large interval of $f$-values for different sized fires was studied throughout the summer of 2004 and 2005 to obtain detection without the inclusion of a large number of false alarms near the clouds. Finally, three different values were used, $f=[2.9,3.0,3.1]$, which means three different levels of probability in the detected fire. Cloud filtering by means of channel $10.8 \mu \mathrm{m}$ has been used to remove low temperature points (Casanova et al. 2005). It must be stated at this point that a contextual detection algorithm applied to MSG images would be wholly inadequate to obtain suitable results due to the appearance of false alarms but adapted to support the detection of HTE once they have started. Thus, false alarms are reduced, since the contextual process is applied expressly on the points that are already candidates. Also, an additional filter was applied, selecting a fire when it is itself repeated in at least two consecutive scenes; it may be possible to lose the first half hour of fire development, but it would never affect results, since analysed fires had several hours of development.

\section{Validation results}

There are several factors that influence validation processes when sensors of different resolutions are to be taken into account. In the case of forest fires, validation should also considerer two other key aspects: to check if detection algorithm is sensible, minimizing omission errors, and selective, minimizing commission errors (false alarms). Concerning the minimum size of detection over the Iberian Peninsula, Calle et al. (2006) have shown that SEVIRI is able to detect fires of less than 1 ha in size, with a fire temperature higher than $600 \mathrm{~K}$. Concerning false alarms, note that the filter of repetition was applied as shown in $\S 3$. 
To compare the results from polar-orbit sensors, spatial resolution is the main factor. SEVIRI has a sampling step of $3 \mathrm{~km}$ in the nadir point; however, this resolution decreases as the latitude increases due to the geostationary orbit. Over the Galicia region, this nominal value of $3 \mathrm{~km}$ is translated in $3.2 \times 4.5 \mathrm{~km}$, approximately. Also, the spatial resolution of thermal channels is actually $4.8 \mathrm{~km}$ with an overlapping of $1.6 \mathrm{~km}$. The consequence of this effect is that radiance coming from a pixel is at times present in several neighbouring pixels. Although this fact may not imply any problems in other applications, it is very important in the case of fire detection, since fires present confusing geometric structures which make it difficult to identify the affected pixels. For example, when only one pixel is affected, and depending on the location of the fire inside the pixel, it frequently shows the typical structure of a 'plus' sign. Other effects related to the Point Spread Function (PSF) make the validation and comparison with other sensors difficult also. The impact of the PSF in the fire-detection process is important because the brightness temperature in the 3.9- $\mu \mathrm{m}$ band decreases when the fire moves away from the pixel centre. In order to quantify this effect for the SEVIRI sensor, when fire is on the border of the PSF $(1.5 \mathrm{~km}$ from the centre) the brightness temperature is $6 \mathrm{~K}$ lower in the north-south direction and $4 \mathrm{~K}$ in the east-west direction for a fire temperature of $400 \mathrm{~K}$. Therefore, the success of the detection algorithm depends on the fire location inside the pixel. Finally, there are several other difficulties caused by the non-instantaneous observations, only in the cases of small fires.

Concerning MODIS data, files of hot spots generated by the MODIS LP DAAC (Thermal Anomalies: MOD14/MYD14) have been used (Justice et al. 2002, Giglio et al. 2003). Such information is obtained from thermal bands of $1-\mathrm{km}$ spatial resolution using both Terra and Aqua platforms, with a tracking time over Spain of around 10:00-14:00 and 21:30-02:30 UTC. Note that in most cases, fires were active for more than $12 \mathrm{~h}$ during this episode. Therefore, the effect of non-instantaneous observations is not significant for moderate/large fires.

For the second type of validation, a map of burnt areas, generated from a Resourcesat-1-AWiFS image dated on 21 August 2006, was used (González-Alonso et al. 2007). This sensor (with a swath width of $740 \mathrm{~km}$ ), provides data of $56-70-\mathrm{m}$ spatial resolution in four spectral bands. For this work, a cartography of burnt areas, with a pixel size of $60 \mathrm{~m}$, was generated using the red $(0.620-0.680 \mu \mathrm{m})$ and near-infrared $(0.77-0.86 \mu \mathrm{m})$ band. Validation of SEVIRI fire detections was proposed by comparison between the number of fires detected and the burnt area estimated by AWiFS sensor. The resampling process of the grid into a projection maintaining area is required in the case of studies on a global scale. In order to use true-ground data sets of burnt area, a reduced area was considered (no more than $2^{\circ}$ in latitude), in UTM projection. The quantitative error in the $R^{2}$ coefficient is neglected.

Figure 2 shows the three maps used in the validation analysis. The first map shows the hot spots detected by SEVIRI. All detections available, during the period 1-20 August 2006, were considered, although most fire locations appeared repeated for several hours and days. In particular, 3208 hot spots were detected in the study period, taking into account repetitions in time. The second map shows MODIS hotspot locations for the same period of time, which resulted in 3340 hot spots. Finally, the third map shows burnt areas estimated by means of the AWiFS sensor (93260 ha.). 


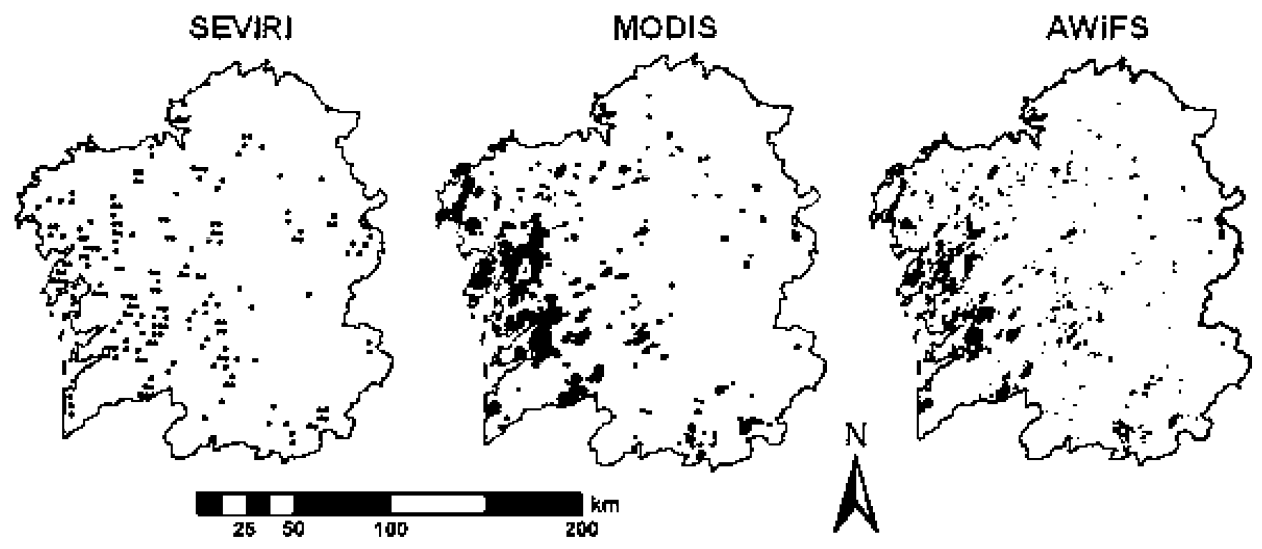

Figure 2. Hot spots detected by SEVIRI and MODIS and burnt area estimated by AWiFS. The differences observed in the picture, SEVIRI and MODIS, are caused by different spatial resolutions.

The proposed methodology of validation considers the region of interest as being divided by a superposed grid of different sizes. In each cell of the grid, the correlation between fires detected by SEVIRI and MODIS is calculated. In the case of SEVIRI and AWiFS, the analysis of the correlation was performed between detected fires and burnt area (ha). Concerning grid size, seven different values of square cells were considered: $3,4,8,10,20,40$, and $80 \mathrm{~km}$ side. With the aim to show a relationship between cell size and the extension of the region of interest, 3597 cells were required to cover the whole region in the case of $3 \times 3 \mathrm{~km}^{2}$, and nine cells were required in the case of $80 \times 80 \mathrm{~km}^{2}$. The magnitude of interest in the analysis of each grid size (GS) was the coefficient of determination $\left(R^{2}\right)$. Note that cells with non-fire locations (SEVIRI\&MODIS) or non-fire and non-burnt-area (SEVIRI\&AWiFS) were eliminated from the analysis to avoid any bias in the statistics.

Figure 3 shows the correlation results, $R^{2}$ vs grid size, for the two analyses. The first part of figure 3 corresponds to the analysis of the correlation between the number of fires detected by SEVIRI and MODIS in each cell. The second part shows the same analysis for fires detected by SEVIRI and the burnt area as estimated by AWiFS.
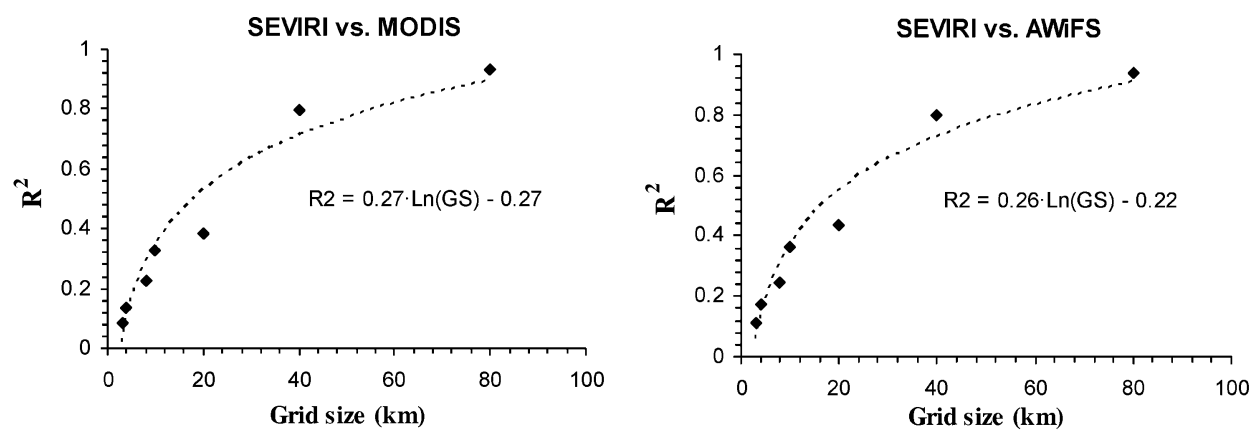

Figure 3. Relationship between $R^{2}$ and grid size for SEVIRI-MODIS and SEVIRI-burnt area AWiFS. 
Figure 3 reveals a similar behaviour of $R^{2}$ as a function of grid size. For small grid sizes $(3,4$, and $8 \mathrm{~km})$, the correlation was not satisfactory $\left(R^{2}\right.$ values were very low). This result was expected, since the spatial resolution of SEVIRI on Galicia is around $15 \mathrm{~km}^{2}$. Grid sizes of 10 and $20 \mathrm{~km}$ showed a higher correlation with similar values. Nevertheless, the value of $40 \mathrm{~km}$ showed a valuable discontinuity with respect to the last lower values of grid size. In both cases, $R^{2}$ for $\mathrm{GS}=40 \mathrm{~km}$ is $0.8(R=0.89)$. The most important aspect of this result is that a larger GS, such as $80 \mathrm{~km}$, shows a similar $R^{2}$ coefficient, as in the case of $40 \mathrm{~km}$. Figure 3 shows a superposed logarithmic spline to explain this conclusion; therefore, $40 \mathrm{~km}$ is the appropriate spatial scale of comparison between hot-spot detection from SEVIRI and polarorbit sensors.

\section{Conclusions and implications}

The international community of users feels that a real-time global observation network may become reality by means of geostationary sensors such as GOES, MSG, and MTSAT. This is one of the objectives of the Global Observations of Forest Cover and Land Cover Dynamics (GOFC/GOLD) FIRE Mapping and Monitoring programme, focusing internationally on decision-making concerning research into climate change and its ecological and environmental implications. Major efforts are also being made by ESA-EUMETSAT to increase the use of MSG in environmental observation tasks, such as those included in the Research Announcement of Opportunity to which the present work belongs.

The last workshop held at EUMETSAT (Darmstadt, Germany) supported by the group GOFC-GOLD, '2nd Workshop on Geostationary Fire Monitoring and Applications', was a very interesting meeting where several algorithms of hot-spot detection were proposed to MSG-SEVIRI, producing results for African and Mediterranean countries. Several physical aspects were discussed. Several projects founded by ESA are working in real time during the summer campaigns, involving different sensors, polar orbiting sensors (e.g. MODIS), and geostationary sensors (e.g. SEVIRI), with the objective of comparing and generating maps of fire occurrence. To do this, several aspects related to scale of validation are required, in order to propose a realistic protocol of validation results. Frequently, this aspect is forgotten or not taken into account, and final conclusions are not realistic.

This Letter shows the appropriate spatial scale of validation for MSG-SEVIRI forest-fire detection in the Iberian Peninsula, and in general for the rest of Mediterranean countries with the same latitude.

Detection and mapping of forest fires using geostationary sensors (MSGSEVIRI) seem to be reliable on national to global scales, as shown by the $R^{2}$ obtained. Results may be considered acceptable on the two methods of validation using a $40-\mathrm{km}$ grid size; $R^{2}=0.79$ (SEVIRI vs. MODIS) and 0.80 (SEVIRI vs AWiFS). This spatial resolution seems also to be adequate for the assessment of $\mathrm{CO}_{2}$ emissions due to biomass burning on global scales using active fire observations (Giglio et al. 2006).

\section{Acknowledgements}

This work has been carried out within the 2000 ESA_EUMETSAT MSG Research Announcement of Opportunity ID 2136, entitled 'Development of an algorithm for the detection and monitoring of forest fires in the Mediterranean area'. The authors wish to thank the institutions that have made this work possible. Also, the authors 
want to acknowledge the MODIS Forest Fire Research Team of the Maryland University for providing MODIS hot-spot data; finally, the authors wish to thank the referees for their helpful comments.

\section{References}

Calle, A., Casanova, J.L. and Romo, A., 2006, Fire detection and monitoring using MSG Spinning Enhanced Visible and Infrared Imager (SEVIRI) data. Journal of Geophysical Research, 111, G04S06, doi: 10.1029/2005JG000116G04S06.

Casanova, C., Romo, A., Hernandez, E., Casanova, J.L. and Sanz, J., 2005, Rapid response for cloud monitoring through Meteosat VIS-IR and NOAA-A/TOVS image fusion: civil aviation application. A first approach to MSG-SEVIRI. International Journal of Remote Sensing, 26, pp. 1699-1716.

Crutzen, P.J., Heidt, L.E., Krasnec, J.P., Pollock, W.H. and Seiler, W., 1979, Biomass burning as a source of atmospheric gases $\mathrm{CO}, \mathrm{H}_{2}, \mathrm{~N}_{2} \mathrm{O}, \mathrm{NO}, \mathrm{CH}_{3} \mathrm{Cl}$ and $\mathrm{COS}$. Nature, 282(5736), p. 253.

Giglio, L., Descloitres, J., Justice, C. and Kaufman, Y., 2003, An enhanced contextual FIRE detection algorithm for MODIS. Remote Sensing of Environment, 87, pp. 273-282.

Giglio, L., van der Werf, G.R., Randerson, J.T., Collatz, G.J. and Kasibhatla, P.S., 2006, Global estimation of burned area using MODIS active fire observations. Atmospheric Chemistry and Physics, 6, pp. 957-974.

González-Alonso, F., Merino, S. and Cuevas, J.M., 2007, Evaluación del área quemada en los incendios forestales de Galicia en agosto 2006 a partir de imágenes AWiFS y focos activos MODIS. $4^{\text {th }}$ International Wildland Fires Conference, 13-17 May, Seville, Spain. Available online at: http://www.wildfires07.es.

Ichoku, C., Kaufman, Y.J., Giglio, L., Li, Z., Fraser, R.H., JiN, J.-.Z. and Park, W.M., 2003, Comparative analysis of daytime fire detection algorithms using AVHRR data for the 1995 fire season in Canada: perspective for MODIS. International Journal of Remote Sensing, 24, pp. 1669-1690.

Justice, C.O., Giglio, L., Korontzi, S., Owens, J., Morisette, J.T., Roy, D., Descloitres, J., Alleaume, S., Peticolin, F. and Kaufman, Y., 2002, The MODIS Fires Products. Remote Sensing of Environment, 83, pp. $244-262$.

Justice, C.O. and Korontzi, S., 2001, A review of satellite fire monitoring and requirements for global environmental change research. In Global and Regional Wildfire Monitoring: Current Status and Future Plans, F.J. Ahern, J.G. Goldammer and C.O. Justice (Eds) (The Hague, Netherlands: SPB Academic Publishing), pp. 1-18.

Kaufman, Y. and Justice, C., 1998, MODIS Fire Products, Algorithm Theoretical Basis Document, MODIS Science Team. EOS ID\#2741.

Li, Z., Kaufman, Y.K., Ichoku, C., Fraser, R., Trishchenko, A., Giglio, L., Jin, J.-Z. and YU, X., 2001, A review of AVHRR-based active fire detection algorithms: Principles, limitations and recommendations. In Global and Regional Vegetation Fire Monitoring from Space: Planning a Coordinated International Effort, F. Ahern, J.M. Gregoire and C. Justice (Eds) (The Hague, The Netherlands: SPB Academic Publishing), pp. 199-225.

Malingreau, J.P., 1990, The contribution of Remote Sensing to the global monitoring of fires in tropical and subtropical ecosystems, Fire in the tropical Biota. In Ecosystem Processes and Global Challenges, J.G. Goldammer (Ed.), pp. 337-399 (Berlin: Springer).

Prins, E.M. and MenZeL, W.P., 1992, Geostationary satellite detection of biomass burning in South America. International Journal of Remote Sensing, 13, pp. 2783-2799.

Prins, E.M. and Menzel, W.P., 1994, Trends in South American burning detected with the GOES VAS from 1983-1991. Journal of Geophysical Research, 99(D8), pp. 16719-16735. 
Prins, E., Govaerts, Y. and Justice, C.O., 2004, Report on the Joint GOFC/GOLD Fire and CEOS LPV Working Group Workshop on Global Geostationary Fire Monitoring Applications. In GOFC/GOLD Report, No.19, 23-25 March 2004 (Darmstadt, Germany: EUMETSAT).

Prins, E., Schmetz, J., FlynN, L., Hillger, D. and Fetz, J., 2001, Overview of current and future diurnal active fire monitoring using a suite of international geostationary satellites. Global and Regional Wildfire Monitoring: Current Status and Future Plans, F.J. Ahern, J.G. Goldammer, and C.O. Justice (Eds) (The Hague, Netherlands: SPB Academic Publishing), pp. 145-170.

Roberts, G., Wooster, M.J., Perry, G.L.W., Drake, N., Rebelo, L.M. and Dipotso, F., 2005, Retrieval of biomass combustion rates and totals from fire radiative power observations: Application to southern Africa using geostationary SEVIRI imagery. Journal of Geophysical Research, 110, D21111, doi: 10.1029/2005/D006018.

Schmetz, J., Pili, P., Tuemkes, S., Just, D., Kerkmann, J., Rota, S. and Ratier, A., 2002, An introduction to Meteosat Second Generation (MSG). Bulletin of the American Meteorological Society, 83, pp. 977-992.

Wooster, M.J., Roberts, G., Perry, G.L.W. and Kaufman, Y.J., 2005, Retrieval of biomass combustion rates and totals from fire radiative power observations: FRP derivation and calibration relationships between biomass consumption and fire raditive energy release. Journal of Gephysical Research, 110, D24311. 